\title{
ANALISIS SWOT DALAM PELAKSANAAN PENGELOLAAN TEMPAT EVAKUASI SEMENTARA OLEH BPBD KOTA PADANG
}

\author{
Fegi Yani Lakosa \\ Jurusan Administrasi Publik, Fakultas Ilmu Sosial, Universitas Negeri Padang \\ E-mail: fegiyanilakosa30@gmail.com \\ Zikri Alhadi \\ Jurusan Administrasi Publik, Fakultas Ilmu Sosial, Universitas Negeri Padang \\ E-mail: ianunpzikri@yahoo.co.id
}

\begin{abstract}
The purpose of this study is to analyze strengths, weaknesses, opportunities, and threats faced by the Padang city BPBD in managing temporary evacuation sites. This type of research is qualitative with descriptive methods. The results of this study indicate that the strength of the Regional Disaster Management Agency in the City of Padang in managing this temporary evacuation site is to have a legal basis such as a Decree issued by the Padang BPBD Chief of Management in conducting management, law number 24 of 2007 concerning countermeasures disaster and law number 28 of 2002 concerning building. As for the Weaknesses faced are human resources and the limited budges for managing temporary evacuation sites. Then what becomes an opportunity is that the existence of the legal basis provides an opportunity to collaboration with other organizations in evaluating the management of temporary evacuations sites. Furthermore, the threat faced is the presence of irresponsible people who take electrical equipment arround the temporary evacuations site
\end{abstract}

Keywords: SWOT analyze, temporary evacuation site, padang city BPBD

How to Cite: Fegi Yani Lakosa dan Zikri Alhadi. 2019. Analisis SWOT dalam Pengelolaan Tempat Evakuasi Sementara Oleh BPBD Kota Padang. 3(2): pp. 57-66. DOI: https://doi.org/10.24036/jess/vol3-iss2

\section{Pendahuluan}

Dengan terjadinya gempa yang terjadi pada beberapa tahun yang lalu pemerintah Kota Padang sadar akan resiko bencana yang dihadapi karena Sumatera Barat khususnya Kota Padang rawan akan bencana tsunami. Mengacu pada pasal 57 yang terdapat didalam Undang-Undang Nomor 24 tahun 2007 tentang Penanggulangan Bencana menyebutkan bahwa penyelenggaraan penanggulangan bencana yang terjadi pada tahap pascabencana meliputi rehabilitasi dan rekonstruksi. Pelaksanaan ketentuan rekonstruksi bangunan tersebut dijelaskan 
dalam Peraturan Pemerintah Nomor 64 tahun 2010 tentang Mitigasi Bencana di wilayah Pesisir dan Pulau-pulau Kecil. Pada pasal 15 ayat (2) menjelaskan bahwa kegiatan struktur/fisik untuk mitigasi terhadap jenis bencana tsunami sebagaimana dimaksudkan dalam pasal 3 ayat (2) huruf b menyatakan bahwa salah satunya disebutkan adanya penyediaan fasilitas penyelamatan diri, maksudnya dengan membangun banguann Tempat Evakuasi Sementara (TES).

Maksud dari bangunan tempat evakuasi sementara ini adalah fasilitas umum yang digunakan pada saat terjadi bencana tsunami digunakan sebagai tempat evakuasi, dan jika dalam keadaan normal atau tidak terjadi bencana bisa digunakan untuk tempat rekreasi, senam, dll. Sedangkan bangunan yang berpotensial TES ada 80 (delapan puluh) bangunan yang berpotensial TES yang tersebar di wilayah Kota Padang dan masih banyak lagi wilayah yang belum ada tempat evakuasinya. Sedangkan wilayah yang paling banyak terpapar resiko bencana adalah Kota Padang dan sekitarnya. BPBD dan juga Pemda seharusnya sudah memperhitungkan jumlah TES yang akan dibangun serta menyediakan minuman, makanan ringan di dalam TES, sebab jika terjadi bencana masyarakat tidak dapat meninggalkan TES tersebut sebelum adanya informasi bahwa kondisi sudah aman dari bencana. Berdasarkan pernyataan tersebut bangunan tempat evakuasi ini sangat jarang dihuni dan diberi pemeliharaan sebagaimana dalam Undang-Undang Nomor 28 Tahun 2002 tentang Bangunan Gedung. Meski sudah dijelaskan di dalam undang-undang Nomor 28 Tahun 2002 tentang Bangunan Gedung, diantaranya bagaimana seharusnya gedung itu diberi pemeliharaan, perawatan, dan pemeriksaan secara berkala, namun di lapangan masih banyak ditemukan tempat evakuasi sementara itu dalam kondisi bangunan yang kurang di perhatikan oleh pihak-pihak terkait yang mengakibatkan sebagian TES terlihat kotor dan tidak terawat.

Hal serupa juga dikatakan oleh Sekda Kota Padang yang dikutip dari berita Okezone.com yang diposting pada hari jumat tanggal 3 februari 2017 yang mengatakan bahwa tempat evakuasi sementara yang ada di Kota Padang belum bisa dikatakan layak untuk dijadikan tempat pengungsian. Karena sarana dan prasarana yang belum memadai, termasuk faktor penunjang lainnya seperti akses menuju TES serta daya tahan gempa.

Tabel 1. Lokasi Tempat Evakuasi Sementara (TES) Kota Padang

\begin{tabular}{cccccc}
\hline Lokasi & Alamat & Fungsi & Jumlah lantai & $\begin{array}{c}\text { Daya } \\
\text { tampung }\end{array}$ & $\begin{array}{c}\text { Uji } \\
\text { kelayakan }\end{array}$ \\
\hline $\begin{array}{c}\text { TES Nurul } \\
\text { Haq }\end{array}$ & $\begin{array}{c}\text { Komplek Jondul } \\
\text { 4 Parupuak } \\
\text { Tabing, Koto } \\
\text { Tangah }\end{array}$ & TES & 6 (dak beton) & 1.000 & Belum \\
& $\begin{array}{c}\text { Kel. Bungo } \\
\text { Pasang }\end{array}$ & TES & 6 (dak beton) & 1.000 & Belum \\
TES & Jl. Sumatera & TES & 4 (dak beton) & & Belum \\
\hline $\begin{array}{c}\text { TES Wisma } \\
\text { Indah Warta } \\
\text { Bunda }\end{array}$ & Ulakkarang & & & & \\
\hline $\begin{array}{c}\text { Sumber: BPBD Kota Padang } \\
\text { Sumballam }\end{array}$ & & & &
\end{tabular}


Berdasarkan tabel di atas dapat kita pahami bahwa jumlah Tempat Evakuasi Sementara yang ada di Kota Padang baru berjumlah 3 unit diantaranya penanggung jawab dari tempat evakuasi sementara itu ialah BPBD Kota Padang yang memiliki daya tampung lebih dari cukup dan tempat evakuasi sementara tersebut belum di uji kelayakannya karena TES tersebut sudah didesain khusus untuk tempat evakuasi sementara. Akan tetapi semenjak peresmiannya, bangunan tempat evakausi sementara tersebut belum di manfaatkan secara maksimal oleh masyarakat setempat dan hanya menjadi bangunan kosong serta menjadi tempat sebagian orang melakukan penyimpangan atau perilaku yang tercela, seperti: yang dikutip dari berita Padang Ekspres yang diposting pada tanggal 1 Oktober 2018 salah satu warga masyarakat Ulak Karang menyampaikan keresahan masyarakat terhadap prilaku remaja yang memanfaatkan bangunan gedung tempat evakuasi sementara tersebut untuk melakukan penyimpangan seperti berbuat maksiat, sodomi, dan menghisap lem.

Berdasarkan latar belakang masalah di atas penulis merumuskan permasalahan sebagai berikut: bagaimanakah kekuatan, kelemahan, peluang dan ancaman (SWOT) yang dihadapi BPBD Kota Padang dalam melaksanakan pengelolaan tempat evakuasi sementara

\section{Tinjauan Kepustakaan}

\section{Konsep Bencana dan Manajemen Bencana}

Bencana menurut United Nations develompment Program (UNDP), dalam Ramli (2010) mengatakan bahwa bencana adalah suatu kejadian yang ekstrem dalam lingkungan alam, atau manusia yang secara merugikan mempengaruhi kehidupan manusia, harta, benda, atau aktivitas sampai pada tingkat yang menimbulkan bencana.

Faktor-faktor bencana terbagi menjadi:

1. Bahaya yang diakibatkan oleh faktor geologi yakni: gempa, longsor, letusan gunung api, tsunami, dan lain sebagainya.

2. Bahaya yang disebabkan oleh faktor klimatologi yaitu: banjir, kekeringan, badai, topan,

3. Bahaya yang diakibatkan dari ekologis diantaranya: tumpahan minyak, pencemaran limbah industri, tambang, kerusakan ekosistem,

4. Dan yang terakhir bahaya yang diakibatkan dari antropogenik meliputi: kebakaran, kerusakan sosial, kebocoran gas beracun, kerusuhan sosial.

Manajemen bencana menurut Ramli (2010) mengatakan bahwa upaya untuk menanggulangi semua kejadian bencana secara cepat, tepat, dan akurat untuk meminimalisir korban, dan juga kerugian yang ditimbulkan. Hal serupa juga dinyatakan oleh pendapat shaluf dalam Kusumasari (2014) manajemen bencana merupakan sebagai istilah kolektif yang mencangkup semua aspek perencanaan untuk merespon bencana, termasuk kegiatan-kegiatan yang dilakukan sebelum dan sesudah bencana yang kemungkinan merujuk pada manajemen resiko dan konsekuensi bencana. Sedangkan menurut Nurrjanah (2012) dalam (Azmi Sahid 
Fillah, n.d.) menjelaskan bahwa Manajemen Bencana adalah ilmu pengetahuan yang mempelajari bencana beserta gejala aspek yang berkaitan dengan bencana, terutama resiko bencana. Dari penjelasan diatas dapat kita pahami bahwa dengan adanya bangunan tempat evakuasi sementara sudah berupaya untuk menanggulangi bencana dan meminimalisir korban yang ada.

Tingkat kerawanan resiko bencana di Kota Padang cukup tinggi sehingga masyarakat dan juga pihak BPBD Kota Padang maupun BNPB membangun sebuah tempat evakuasi sementara di beberapa titik daerah yang termasuk zona merah. Jadi menurut penulis, manajemen bencana itu adalah suatu ilmu yang mempelajari semua tentang bencana baik itu dalam segala aspek mulai dari resiko bencana sampai bagaimana cara untuk menghindari resiko bencana itu sendiri.

\section{Konsep Tempat Evakuasi Sementara}

Tempat evakuasi sementara adalah banguanan yang ditujukan untuk tempat evakuasi apabila terjadi bencana dan jika tidak terjadi bencana (keadaan normal) dapat digunakan sebagai fasilitas umum seperti tempat ibadah, sosialisasi, dan lainnya. Penentuan TES tsunami sangat penting dilakukan terutama di daerah yang rawan terhadap bahaya tsunami serta memiliki topografi yang rendah dan jauh dari daerah topografi tinggi (aman dari bahaya tsunami). Terdapat beberapa persyaratan agar bantuan tersebut dapat dijadikan bangunan evakuasi tsunami:

1. Bangunan tersebut tahan gempa bumi

2. Memiliki jumlah lantai yang cukup aman (lebih tinggi dari perkiraan tinggi tsunami)

3. Dalam kondisi normal (tidak terjadi bencana tsunami), bangunan tersebut dapat berfungsi sebagai bangunan umum, sehingga memenuhi aspek keberlanjutan (sustainability)

Bangunan gedung TES tsunami ini berbeda dengan menara TES. Bangunan ini dapat digunakan untuk kegiatan masyarakat. Bangunan gedung TES tsunami letaknya harus dilokasi keramaian yang strategis dan mudah dijangkau. Bangunan TES ini, juga dapat bersifat bangunan umum seperti masjid, sekolah, rumah sakit, kantor, hotel dan sebagainya yang dapat digunakan sebagai tempat evakuasi, Yuhanah (2014) menyatakan bahwa yang menjadi peran penting dalam menntukan tempat evakuasi sementara adalah bangunan harus dapat bertahan dari bencana dan mempunyai lantai di atas tingkat genangan tsunami. Persyaratan khusus dibutuhkan agar bangunan dapat bertugas sebagai tempat evakuasi diantaranya:
a. Struktur
b. Lantai evakuasi
c. Fungsi
d. Rancangan dan Kapasitas
e. Lokasi atau Kemudahan Akses
f. Kemudahan akses vertikal Keamanan 


\section{Konsep Analisis SWOT}

Dalam melakukan pengelolaan tempat evakuasi sementara BPBD Kota Padang menghadapi beberapa faktor yang dibagi menjadi faktor internal dan faktor eksternal. Faktor internal terdiri dari kekuatan dan kelemahan. Yang dimaksud dengan kekuatan menurut Salusu (2015) adalah sebuah organisasi yang memiliki keuntungan dalam mencapai sasarannya. Adapun yang menjadi kekuatan BPBD Kota Padang dalam melakukan pengelolaan tempat evakuasi sementara adalah memiliki landasan hukum. Kelemahan menurut Hadi (2013) adalah adanya keterbatasan di sebuah organisasi sehingga menghambat tercapainya tujuan sebuah organisasi. Kelemahan yang dihadapi BPBD Kota Padang dalam melakukan pengelolaan tempat evakuasi sementara adalah terletak pada sumber daya manusianya dan juga terbatasnya anggaran. Faktor eksternal terdiri dari peluang dan ancaman. Dalam Salusu (2015) pengertian peluang adalah segala bentuk dan situasi yang menguntungkan bagi suatu organisasi. Adapun yang menjadi peluang bagi BPBD Kota Padang dalam melakukan pengelolaan ini adalah adanya bentuk kerjasama dari berbagai pihak. Ancaman dalam Salusu (2015) adalah faktor lingkungan yang tidak menguntungkan bagi organisasi. Yang menjadi ancaman bagi pihak BPBD Kota Padang ialah adanya orang-orang yang tidak bertanggungjawab yang mengambil alat-alat listrik disekitaran tempat evakuasi sementara.

\section{Metode Penelitian}

Penelitian ini merupakan penelitian kualitatif dengan metode deskriptif. Dimana penelitian ini merupakan memberikan gambaran mengenai suatu fenomena yang terjadi dan diamati secara alamiah dengan fakta-fakta yang akurat. Penelitian dilakukan di kantor BPBD Kota Padang, dan juga TES yang ada di Kota Padang. Informan dalam penelitian ini adalah Kabid, Kasi, dan juga Staff BPBD Kota Padang serta Ketua pengelola TES dan juga masyarakat yang berada di lingkungan tempat evakausi sementara. Data yang digunakan adalah data primer dan data sekunder yang berasal dari pengamatan dan observasi yang peneliti lakukan, berupa wawancara dan studi dokumentasi. Data ini diuji keabsahannya dengan teknik triangulasi sumber karena data yang diperoleh merupakan data dari banyak sumber. Teknik triangulasi adalah perbandingan dan pengecekkan balik derajat kepercayaan atau informasi melalui orang-orang sebagai sumber yang berbeda. Data ini kemudian dianalisis dengan teknik analisis data kualitatif, mulai dari reduksi data, penyajian data, dan verifikasi data.

\section{Hasil Penelitian dan Pembahasan}

\section{Hasil Penelitian}

Berdasarkan latar belakang yang telah dikemukakan, bahwa penelitian ini akan menjawab rumusan masalah yang telah ada sebelumnya, yaitu: bagaimana kekuatan, kelemahan, peluang dan ancaman yang dihadapi BPBD Kota Padang 
dalam pelaksanaan pengelolaan tempat evakuasi sementara, jawaban dari rumusan masalah penelitian telah dijelaskan dalam hasil penelitian sebagai berikut:

\section{Analisis SWOT}

Dalam penelitian ini, analisis SWOT digunakan untuk mengidentifikasi empat faktor utama yang mempengaruhi pelaksanaan pengelolaan tempat evakuasi sementara yang ada di Kota Padang. Adapun empat faktor utama tersebut diantaranya:

\section{Kekuatan (strengths)}

Kekuatan adalah yang berasal dari dalam organisasi yang bersifat positif, yang memungkinkan memiliki keuntungan dalam mencapai sasarannya. Dalam penelitian ini yang menjadi kekuatan dalam melakukan pengelolaan tempat evakuasi sementara adalah adanya landasan hukum yang jelas, adanya peraturan yang jelas itu dapat menjadikan pelaksanaan dalam melakukan pengelolaan tempat evakuasi sementara itu berjalan dengan aturan yang ada. Dengan dikeluarkannya Surat Keputusan dari Kepala Pelaksana BPBD Kota Padang Nomor 14 tahun 2017 tentang Tim Pengelola Shelter Jabbal Nurul Haq Jondul IV Parupuk Tabing dan Surak Keputusan BPBD Kota Padang Nomor 39 Tahun 2017 tentang Tim Pengelola Shelter Darusallam Wisma Indah V Bungo Pasang untuk pengelolaan tempat evakuasi dan juga UndangUndang Nomor 24 tahun 2007 tentang Penanggulangan Bencana berkaitan dengan Mitigasi Bencana yang maksudnya adalah upaya untuk mengurangi resiko bencana melalui pembangunan fisik maupun penyadaran dan peningkatan kemampuan menghadapi ancaman bencana, selain itu ada juga Undang-undang Nomor 28 Tahun 2002 tentang Bangunan Gedung, bagaimana perawatan, pemeliharaan dan lain-lainnya.

\section{Kelemahan (Weaknesses)}

Kelemahan adalah faktor internal yang berasal dari dalam organisasi. Dalam penelitian ini yang menjadi kelemahan BPBD Kota Padang dalam melakukan Pengelolaan tempat evakuasi sementara adalah anggaran yang terbatas dalam melakukan pengelolaan tempat evakuasi sementara sehingga programprogram yang akan di lakukan sedikit terhambat, kemudian kelemahannya terletak pada sumber daya manusianya yang kurang profesional di bidangnya sehingga membuat tugas dari pengelola tempat evakuasi ini kurang optimal. Ada beberapa pegawai yang bekerja di Kantor BPBD Kota Padang yang tidak sesuai dengan bidangnya tetapi tetap melakukan tugas kebencanaan. Selain itu masyarakat yang ditunjuk sebagai Pengelola terdiri dari 12 bidang diantaranya Penanggung Jawab, Penasehat, Pengawas, Pengelola, Bidang Humas, Bidang Pengelola Olah Raga, Bidang Pengelola Sarana dan Prasarana, Aset, dan Dokumentasi, Bidang Keamanan/Pemuda, Bidang Posyandu/Kesehatan, Bidang Pengembangan Usaha, Bidang Kesiapsiagaan dan Tanggap Darurat, dan Bidang Pendidikan. Diantara banyak bidang tersebut ada beberapa yang tidak menjalankan tugasnya dikarenakan tidak 
bergerak dibidang tersebut serta dikarenakan masih bersifat sukarela sehingga masyarakat kurang aktif dalam menjalankan tugas-tugasnya sebagai pengelola, sehingga banyak tempat evakuasi sementara yang terlihat tidak terawat dan kurang dalam pemeliharaannya.

\section{Peluang (Opportunities)}

Peluang adaah sesuatu hal yang menguntungkan bagi suatu organisasi. Berdasarkan hasil penelitian menunjukkan bahwa peluang yang di dapatkan adalah adanya bentuk kerjasama yang di dapat dari organisasi luar dalam rangka mengikuti cofee morning dan juga kerjasama dengan Hotel yang ada di Kota Padang seperti: Hotel Pangeran Beach, Hoterl Grand Zuri, Hotel Axana, Hotel Grand Mall Basko, dan yang lainnya sebagai tempat evakuasi darurat bagi masyarakat yang tidak sempat datang ke TES yang telah disediakan, pihak BPBD Kota Padang telah bekerjasama pihak hotel untuk memperbolehkan masyarakat menggunakan atap atau gedung paling atas hotel untuk tempat evakuasi, dan bagi tempat evakuasi sementara sendiri yaitu dengan adanya sewa gedung yang nantinya akan menjadi uang masuk bagi pengelola tempat evakuasi sementara yang digunakan untuk pembersihan atau pemeliharaan tempat evakuasi sementara.

Tabel 2. Nama-nama Organisasi yang Mengikuti Cofee Morning

\begin{tabular}{|c|c|c|c|}
\hline No. & Nama organisasi & No. & Nama Organisasi \\
\hline 1 & BMKG Padang Panjang & 31. & Pramuka Peduli \\
\hline 2. & Basarnas Kota Padang & 32. & Nissan Terrano Club \\
\hline 3. & PMI Kota Padang & 33. & Relawan Bencana Ranah Minang \\
\hline 4. & Forum PRB Kota Padang & 34. & Bulan Sabit Merah Indonesia \\
\hline 5. & Forum KSB Kota Padang & 35. & $\mathrm{M} \mathrm{H} \mathrm{C} \mathrm{C}$ \\
\hline 6. & Mercy Corps Indoneisa & 36. & Relawan Padang Peduli Bencana \\
\hline 7. & DRR Indonesia & 37. & Karang Taruna Kota Padang \\
\hline 8. & KOGAMI & 38. & Forum Perguruan Tinggi PRB \\
\hline 9. & RAPI Kota Padang & 39. & Pusat Studi Bencana Unand \\
\hline 10. & ORARI Kota Padang & 40. & UIN Imam Bonjol \\
\hline 11. & TAGANA Kota Padang & 41. & Komunitas Trooper indonesia \\
\hline 12. & $\begin{array}{l}\text { Muhamadiyah Disaster Management } \\
\text { Centre (MDMC) }\end{array}$ & 42. & $\begin{array}{l}\text { Pusat Studi Bencana Univ. Bung } \\
\text { Hatta }\end{array}$ \\
\hline 13. & Build Change & 43. & Komite Peduli Bencana (KPB) \\
\hline 14. & TRC Semen Padang & 44. & Perkumpulan Galapagos \\
\hline 15. & Padang Baywatch & 45. & Arbes FM \\
\hline 16. & Padang Emergency Respond & 46. & $\begin{array}{l}\text { KSB Kecamatan } \\
\text { kabung }\end{array}$ \\
\hline 17. & Padang Rescue Peduli & 47. & KSB Kecamatan Koto Tangah \\
\hline 18. & Jemari Sakato & 48. & KSB Kecamatan Kuranji \\
\hline 19. & Sekretariat Bersama Pecinta Alam & 49. & KSB Kecamatan Lubuk Begalung \\
\hline 20. & Senkom Mitra Polri & 50. & KSB Kecamatan Lubuk Kilangan \\
\hline 21. & Calsy FM & 51. & KSB Kecamatan Nanggalo \\
\hline 22. & Kosbema Unand & & \\
\hline 23. & Hyprocates Emergency Team (HET) & 52. & $\begin{array}{llll}\begin{array}{l}\text { Keluarga } \\
(\text { KBRC) }\end{array} & \text { Besar } & \text { rang } & \text { Caniago } \\
\end{array}$ \\
\hline 24. & Menwa Maharuyung & 53. & KSB Padang Barat \\
\hline 25. & Pemuda Pancasila & 54. & KSB Kecamatan Padang Selatan \\
\hline
\end{tabular}




\begin{tabular}{|l|l|l|l|}
\hline 26. & Pemuda Panca Marga & 55. & KSB Kecamatan Padang Timur \\
\hline 27. & MRI-Aksi Cepat Tanggap Sumbar & 56. & KSB Kecamatan Padang Utara \\
\hline 28. & Baznas Kota Padang & 57. & KSB Kecamatan Pauh \\
\hline 29. & Rumah Zakat Sumbar & 58. & PENCAB IOF Padang \\
\hline 30. & Dompet Duaffa Sumbar & & \\
\hline
\end{tabular}

Sumber: BPBD Kota Padang

Dari tabel diatas dapat kita pahami bahwa, banyak organisasi yang mengikuti cofee morning untuk mendiskusikan apa permasalahan yang ada dan mengevaluasi tempat evakuasi sementara.

\section{Ancaman (Threats)}

Ancaman merupakan suatu rintangan bagi suatu organisasi yang tidak menguntungkan. Berdasarkan penelitian ini yang merupakan ancaman bagi pelaksanaan pengelolaan tempat evakuasi sementara adalah rendahnya kesadaran masyarakat dalam menjaga, mengelola, dan memelihara tempat evakuasi sementara yang ada dilingkungan tempat sekitarnya, serta ada orang-orang yang tidak bertanggung jawab yang mengambil alat-alat listrik di sekitaran tempat evakuasi sementara.

\section{Pembahasan}

Berdasarkan hasil penelitian yang peneliti jelaskan diatas, peneliti akan menjelaskan dan menganalisis data yang diperoleh melalui literatur analisis SWOT Pelaksanaan Pengelolaan Tempat Evkauasi Sementara oleh BPBD Kota Padang.

\section{Kekuatan (Strenghts)}

Menurut Barry dalam Salusu (2015) kekuatan adalah suatu situasi yang bersifat positif yang memungkinkan organisasi memiliki keuntungan untuk mencapai sasarannya. Adapun beberapa hal yang menjadi kekuatan dalam pelaksanaan pengelolaan tempat evakuasi sementara ini oleh BPBD Kota Padang adalah memiliki landasan hukum yang jelas. Dengan adanya hukum yang jelas dapat menjadikan pelaksanaan dalam melakukan pengelolaan tempat evakuasi sementara seharusnya berjalan sesuai dengan aturan yang ada. Sesuai dengan Surat Keputusan yang di keluarkan oleh Kepala Pelaksana BPBD Kota Padang, dan Undang-Undang Nomor 24 Tahun 2007 tentang Penanggulangan Bencana yang berkaitan dengan Mitigasi Bencana serta Undang-Undang Nomor 28 Tahun 2002 tentang Bangunan Gedung yang memang sudah seharusnya di cek sarana dan prasarana, perawatan serta pemeliharaan agar bangunan terlihat bagus dan nyaman apabila kita menggunakannya pada saat tidak atau sedang terjadi bencana.

\section{Kelemahan (Weaknesses)}

Menurut Barry dalam Salusu (2015) kelemahan merupakan sesuatu yang berasal dari luar organisasi yang pada umumnya dirasakan seperti lokasi yang jauh dari jangkauan fasilitas umum, contohnya jalan raya, telepon, listrik, sumber daya yang lemah dan sebagainya. Hal serupa juga dirasakan oleh BPBD Kota Padang 
selaku Pengelola Tempat Evakuasi Sementara, yang menjadi kelemahannya adalah dalam bentuk kualitas dan kuantitas BPBD Kota Padang masih rendah, dan juga masyarakat yang ditunjuk sebagai pengelola kurang aktif dalam menjalankan tugasnya sehingga TES terlihat kurang terawat dan juga mulai dari sarana dan prasarana, sumber daya manusianya dan juga terbatasnya anggaran dalam hal perawatan, pembersihan dan juga pemeliharaan.

\section{Peluang (Opportunities)}

Menurut Barry dalam Salusu (2015) mengatakan bahwa peluang adalah suatu hal yang menguntungkan bagi suatu organisasi untuk menjalankan kegiatannya agar mencapai sasaran. Adapun yang menjadi peluang BPBD Kota Padang dalam melakukan pelaksanaan pengelolaan tempat evakuasi sementara ini adalah dengan terbentuknya kerjasama dari organisasi lain dan juga khususnya bagi tempat evakuasi sementara adanya penyewaan gedung untuk acara-acara penting dan sebagai uang masukan untuk kebersihan dan lainnya yang nantinya akan digunakan dalam biaya pengelolaan empat evakuasi sementara.

\section{Ancaman (Threats)}

Menurut Barry dalam Salusu (2015) menyebutkan bahwa ancaman adalah suatu rintangan yang berasal dari luar organisasi. Adapun yang menjadi ancaman bagi pihak BPBD Kota Padang adalah masih rendahnya kesadaran masyarakat dalam menjaga, mengelola, dan memelihara tempat evakuasi sementara yang ada di lingkungannya serta banyaknya orang-orang yang tidak bertanggungjawab mengambil alat-alat listrik yang berada di sekitaran tempat evakuasi sementara.

\section{Penutup}

Berdasarkan hasil penelitian dan pembahasan yang telah penulis uraikan sebelumnya, dapat disimpulkan bahwa, dari segi segi kekuatan, kelemahan, peluang, dan ancaman yang dihadapi BPBD Kota Padang dalam melakukan pengelolaan tempat evakuasi sementara yang menjadi kekuatan BPBD Kota Padang dengan adanya landasan hukum yang jelas, seperti Surat Keputusan yang dikeluarkan oleh Kepala Pelaksana BPBD Kota Padang dalam melakukan Pengelolaan, juga berdasarkan Undang-Undang Nomor 24 Tahun 2007 tentang Penanggulangan Bencana dan Undang-Undang Nomor 22 Tahun 2008 tentang Bangunan Gedung. Kemudian kelemahan yang ada pada BPBD Kota Padang adalah terletak pada sumber daya manusia dan juga terbatasnya anggaran sehingga tidak berjalan secara optimalnya program-program yang dilakukan di tempat evakuasi sementara. Selanjutnya peluang adalah BPBD Kota padang dapat bekerjasama dengan pihak luar dan adanya sewaan gedung yang nantinya dapat digunakan untuk biaya tambahan pemeliharan, perawayan dan lainnya, sedangkan ancaman adalah gangguan dari luar organisasi yakni kurangnya partisipasi masyarakat dalam menjaga dan merawat tempat evakuasi sementara serta banyaknya orang-orang yang idak betanggungjawab.

Berlatar belakang hasil penelitian dan kesimpulan yang telah diuraikan diatas, maka penulis memberikan saran-saran diantaranya: 
1. Lebih meningkatkan partisipasi masyarakat dalam pengelolaan tempat evakuasi sementara, menjaga kebersihan dan merawat tempat evakuasi tersebut karena tempat tersebut dibangun untuk jangka panjang.Kepada pengelola tempat evakuasi sementara diharapkan untuk lebih meningkatkan lagi kesadaran masyarakat dalam menjalankan tugas dan fungsi untuk menunjang pencapaian tujuan dibangunnya tempat evakuasi sementara, pengurus lebih mendorong atau menggerakkan anggota yang lainnya agar mau bekerja sama lebih giat untuk mencapai tujuan secara efektif

2. Sebaiknya keamanan di kawasan TES lebih ditingkatkan lagi sehinngga meminimalisir pencurian terjadi.

\section{DAFTAR KEPUSTAKAAN}

Azmi Sahid Fillah, I. \& M. F. (n.d.). Program Penanggulangan Bencana oleh Disaster Management Center (DMC) Dompet Duafa. Jurnal. Prosiding KS: Riset \& PKM., Vol 3 No 2, 155-291.

Hadi, A. (2013). Konsep Analisis SWOT dalam Peningkatan Mutu Lembaga Madrasah. Jurnal Ilmiah Didaktika: Media Ilmiah Pendidikan Dan Pengajaran, 14 (1): 143-158.

Kusumasari, B. (2014). Manajemen dan Kapabilitas Pemerintah Lokal. Yogyakarta: Gava Media.

Peraturan Pemerintah Nomor 64 Tahun 2010 tentang Mitigasi Bencana di Wilayah Pesisir dan Pulau-Pulau Kecil

Ramli, S. (2010). Pedoman Praktis Manajemen Bencana (Disaster Management). Jakarta: PT. Dian Rakyat.

Salusu, J. (2015). Pengambilan Keputusan Stratejik Untuk Organisasi Publik dan Organisasi Publik Nonprofit. Jakarta: PT. Grasindo.

SK Kepala Pelaksana Badan Penanggulangan Bencana Daerah Kota Padang Nomor 14 Tahun 2017 tentang Tim Pengelola Shelter Jabbal Nurul haq Jondul IV Parupuk Tabing

SK Kepala Pelaksana Badan Penanggulangan Bencana Daerah Kota Padang Nomor 39 Tahun 2017 tentang Tim Pengelola Shelter Darusallam Wisma Indah V Bungo Pasang.

Undang-undang Nomor 28 Tahun 2002 tentang Bangunan Gedung

Yuhanah, T. (2014). Konsep Desain Shelter Mitigasi Tsunami. Jurnal Teknologi, Vol 6 No 1 . 